\title{
Allergic Contact Dermatitis Due to Cervical Collar
}

\author{
Prasad Krishnan $^{10} \quad$ Grandhi Aditya $^{1}$ \\ ${ }^{1}$ Department of Neurosurgery, National Neurosciences Centre, \\ Calcutta, West Bengal, India \\ J Neurosci Rural Pract 2022;13:159-160.
}

\begin{abstract}
Address for correspondence Prasad Krishnan, MS, MCh, Department of Neurosurgery, National Neurosciences Centre, 2nd Floor, Peerless Hospital Campus, 360, Panchasayar, Garia 700094, Kolkata, West
\end{abstract} Bengal, India (e-mail: prasad.krishnan@rediffmail.com).
Abstract
Keywords
- allergic contact dermatitis
- Casal's collar
- cervical collar
- complications

Cervical collars are routinely applied in neurosurgical units following trauma or cervical spine operations. We describe a case of florid allergic contact dermatitis that developed as a complication following collar application in a postoperative patient.
A 30-year-old lady underwent an anterior cervical discectomy for a $\mathrm{C} 5-\mathrm{C} 6$ disc prolapse causing radiculopathy. Postoperatively, she was put on a Philadelphia collar and discharged 3 days following surgery. She presented 2 weeks later with an intensely pruritic, erythematous, sharply demarcated rash on the neck, lower part of the face, and upper part of the chest (-Fig. 1). The rash resembled dermatitis seen in niacin (Vitamin B3) deficiency-Casal's collar. As she had no other features of pellagra and considering the localized nature and time frame in which the rash developed, allergic contact dermatitis was diagnosed. She was treated with removal of the collar and application of topical steroid ointments with which the lesion regressed completely in 3 weeks.

Allergic contact dermatitis is a type 4 delayed hypersensitivity response mediated by $\mathrm{T}$ lymphocytes when a patient's skin comes in contact with an allergen. ${ }^{1}$ It is the commonest inflammatory disease of the skin and as in our case occurs more in women than in men. ${ }^{1}$ Despite the fact that common complications seen due to cervical collar applications such as erythema, skin breakdown, and pressure ulcers have been reported to occur in 7 to $23 \%$ of adults, ${ }^{2}$ these are neither something that the patients are counseled

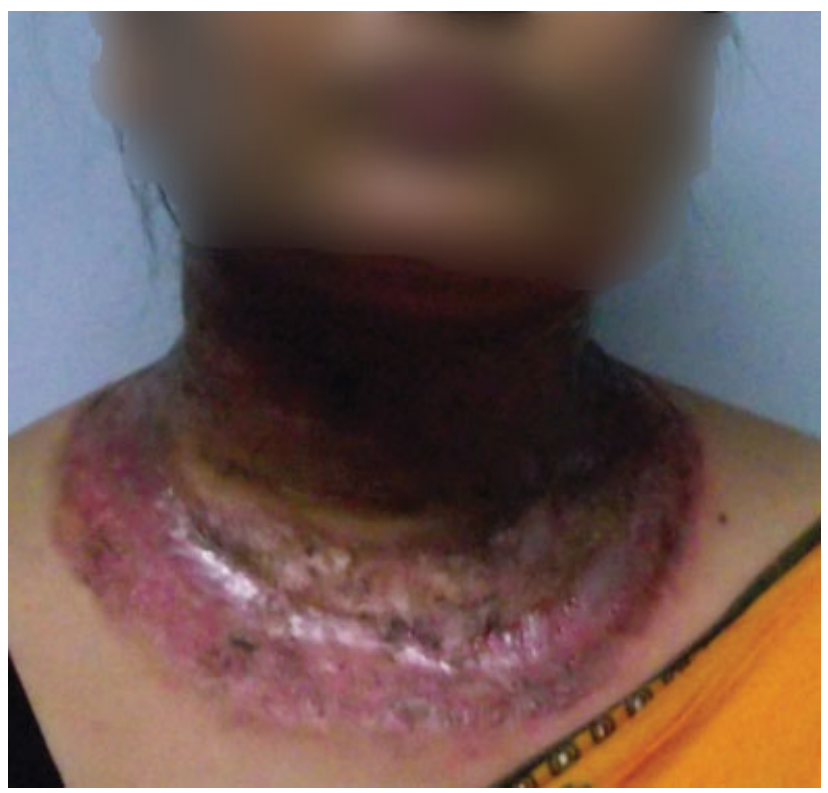

Fig. 1 Clinical image of a patient with sharply demarcated, erythematous rash on the neck following application of a cervical collar for 2 weeks. published online January 5, 2022
DOI https://doi.org/

10.1055/s-0041-1740454. ISSN 0976-3147. (c) 2022. Association for Helping Neurosurgical Sick People. All rights reserved.

This is an open access article published by Thieme under the terms of the Creative Commons Attribution-NonDerivative-NonCommercial-License, permitting copying and reproduction so long as the original work is given appropriate credit. Contents may not be used for commercial purposes, or adapted, remixed, transformed or built upon. (https://creativecommons.org/ licenses/by-nc-nd/4.0/)

Thieme Medical and Scientific Publishers Pvt. Ltd., A-12, 2nd Floor, Sector 2, Noida-201301 UP, India 
about nor an issue that surgeons usually bear in mind while treating patients. Webber-Jones et $\mathrm{al}^{3}$ have cautioned that areas of skin damage carry a risk of bloodstream infections. While some of these complications can be prevented by the addition of extra padding ${ }^{4}$ at pressure points, allergic contact dermatitis as seen in our case has never before been reported in the literature and mandates doing away with the offending collar altogether.

\section{Conflict of Interest}

None declared.

\section{References}

1 Murphy PB, Atwater AR, Mueller M. Allergic contact dermatitis. [Updated 2021 Jul 26] In: StatPearls [Internet]. Treasure Island (FL): StatPearls Publishing; 2021. Available from: https://www. ncbi.nlm.nih.gov/books/NBK532866/

2 Chan M, Al-Buali W, Charyk Stewart T, et al. Cervical spine injuries and collar complications in severely injured paediatric trauma patients. Spinal Cord 2013;51(05):360-364

3 Webber-Jones JE, Thomas CA, Bordeaux RE Jr. The management and prevention of rigid cervical collar complications. Orthop Nurs 2002;21(04):19-25, quiz 25-27

4 Liew SC, Hill DA. Complication of hard cervical collars in multitrauma patients. Aust N Z J Surg 1994;64(02):139-140 